Paper ID \#17613

\title{
Educational Support through the Career Life-Span of Professional Working Adult Learners: An Integrative Theoretical and Experiential Reflection from the Learner's Perspective
}

\author{
Dr. Mitchell L Springer PMP, SPHR, Purdue University, West Lafayette (College of Engineering)
}

\begin{abstract}
Dr. Mitchell L. Springer PMP, SPHR, SHRM-SCP
Dr. Springer currently serves as an Executive Director for Purdue University's Polytechnic Institute located in West Lafayette, Indiana. He has over 35 years of theoretical and Defense industry-based practical experience from four disciplines: Software Engineering, Systems Engineering, Program Management and Human Resources. Dr. Springer possesses a significant strength in pattern recognition, analyzing and improving organizational systems. He is internationally recognized, has contributed to scholarship more than 200 books, articles, presentations, editorials and reviews on software development methodologies, management, organizational change, and program management. Dr. Springer sits on many university and community boards and advisory committees. He is the recipient of numerous awards and recognitions, most recently, the Purdue University, College of Technology, Equity, Inclusion and Advocacy Award. Dr. Springer is the President of the Indiana Council for Continuing Education as well as the Chair of the Continuing Professional Development Division of the American Society for Engineering Education.
\end{abstract}

Dr. Springer received his Bachelor of Science in Computer Science from Purdue University, his MBA and Doctorate in Adult and Community Education with a Cognate in Executive Development from Ball State University. He is certified as a Project Management Professional (PMP), Senior Professional in Human Resources (SPHR \& SHRM-SCP), in Alternate Dispute Resolution (ADR), and, in civil and domestic mediation. Dr. Springer is a State of Indiana Registered domestic mediator.

\section{Mr. Mark T Schuver, Purdue University, West Lafayette (College of Engineering)}

Mark Schuver is the Director for the Center for Professional Studies in Technology and Applied Research (ProSTAR) in the Polytechnic Institute at Purdue University in West Lafayette, Indiana. He is responsible for the administration/operations of the Center with Program Management oversight of the Rolls-Royce Master of Science Degree, the Construction Management Master of Science Degree and Product Lifecycle Management Certificate Programs for working professionals. Prior to joining Purdue in 2002, Mark was employed by Caterpillar, Inc for 35 years with assignments in Product Design, Research and Development, Supplier Management, Quality Management, Logistics Management and various leadership positions. He holds an Associate Degree in Drafting Technology from North Iowa Area Community College, a BS in Business Administration and MS in Management from Indiana Wesleyan University.

Mark is a member of the American Society for Engineering Education and serves on the Executive Board of the Continuing Professional Development Division. He is also a member of College/Industry Partnerships, Engineering Technology and Graduate Studies Divisions of ASEE. Mark is a Lifetime Certified Purchasing Manager with the Institute of Supply Management (formerly NAPM). 


\title{
Educational Support through the Career Life-Span of Professional Working Adult Learners: An Integrative Theoretical and Experiential Reflection from the Learner's Perspective
}

\begin{abstract}
Life-span career educational needs of professional working adult learners are premised on a selfperspective that is multi-faceted. At the lowest level are underlying foundational needs of motivation; this given there is an expected and desired outcome from an applied level of effort. As careers progress, there is an acute awareness of the remaining opportunities available for professional pursuit; this frequently is referred to as having "a short runway”, and, is the underlying basis for pursuing educational opportunities correspondingly aligned.

Aside from the many fleeting opportunities attendant to an aged career, there are numerous life phase motivators, as well as those attendant to biological, psychological and cognitive changes that have a direct impact on desire and/or willingness to exert energies toward educational pursuits.

This paper frames the professional working adult learners' perspective and subsequent educational needs as they progress through their career life spans. Additionally, this paper addresses administrative organizations in meeting these many needs.

\section{Motivation}

The field of motivation seeks to understand the causation of specific actions. Motivation theorists do not necessarily agree with each other about the cause. For example, in a shooting incident: there may be three different perspectives on the cause for the incident ${ }^{11}$.

$\square$ The shooter had a bursting loose of furious anger, perhaps pent up for many years and originally directed at the parents.

- The shooter had a history of reinforcement for violent actions. The incident was probably caused by a lack, or absence, of reinforcement at the present time.

$\square$ The shooting incident was a result of reasoned, if not rational decision making. The individual simply decided that people were the cause for his or her misery.
\end{abstract}

Motivation may be defined as: "The willingness to exert high levels of energy toward organizational goals, conditioned by the effort's ability to satisfy some individual need” (1, p. 50). 
What motivates individuals to produce? Why is it that what seems to motivate one person does not necessarily motivate another? Does our motivation change over time? There are literally hundreds of motivational models in the literature. The model most applicable to this paper is the Expectancy Theory as described below.

Expectancy theory offers one of the most pragmatic and comprehensive explanations of motivation. It was created by Victor Vroom. The theory basically states that the strength of an individual to act in a certain way depends on the strength of an expectation that the act will be followed by a given outcome, and on the attractiveness of that outcome to the individual.

This theory, depicted in figure 1.0 below, focuses on three relationships:

Effort-Performance: probability that exerting a given amount of effort will lead to performance

$\square$ Performance-Reward: performing at a particular level will lead to a desired outcome

$\square$ Reward-Personal goals: degree to which a reward satisfies a personal goal

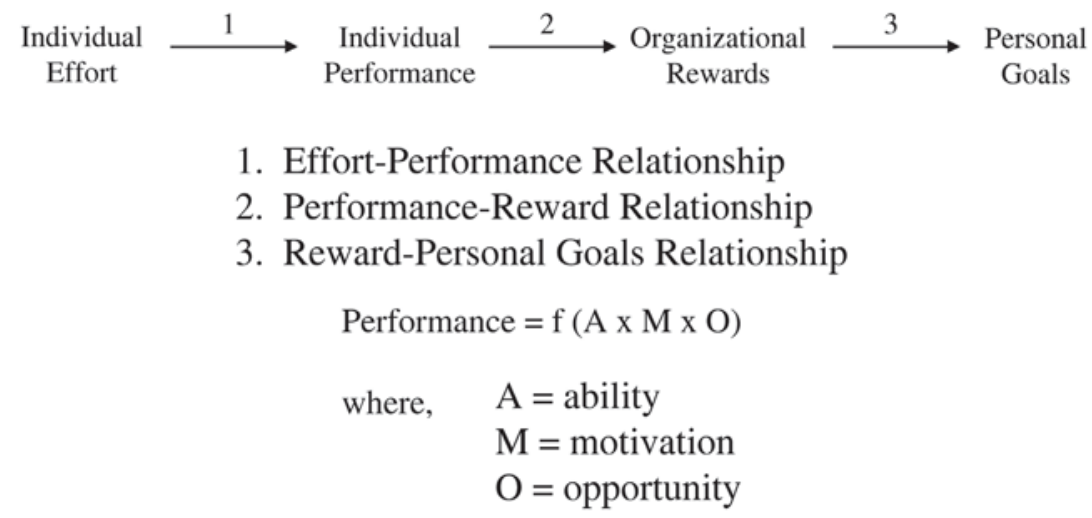

\section{Figure 1.0. Expectancy Theory}

The concept of this model is that individual effort will lead to individual performance, which will lead to organizational goals, and ultimately to personal goals. Performance, however, is a function of the individual's ability, motivation, and opportunity. If either one of the three is insufficient, then the individual may not be able to perform satisfactorily enough to merit organizational rewards perceived necessary to achieve personal goals.

A good example of this is where there is a set of identified and documented abilities, skills, and knowledge necessary to move into the next higher career job grade. However, a job at this next higher level does not have an opening at this time. The individual, therefore, may have all of the 
necessary personal tools to move up, but he or she simply lacks opportunity. If this condition lasts for a prolonged period of time, the individual may seek other employment because he or she cannot satisfy his or her personal goals, or, become complacent and loose site of their goals, resulting in performance degradation. This is a very real challenge in today's flatter organizational models. The solution to this is to provide peer-level, horizontal opportunities that will allow the individual the opportunity for personal growth and financial gain, without having to move vertically in the organization.

\section{Ageing Slows Consumption Patterns -}

As we chronologically age, we have very predictable patterns of spending. These patterns of spending are directly linked to what have been coined gerontological life phases. When we refer to gerontological phases we are referring to the scientific study of human development. The scientific study of human development is the science that seeks to understand how and why people change, and how and why they remain the same, as they grow older ${ }^{(2, \text { p. 40). }}$.

To help individuals to better understand the developmental changes we experience as we grow older, there have been established three domains of human development: biosocial, cognitive, and psychosocial.

Biosocial development includes all of the growth and changes that occur in a person's body, and the genetic, nutritional, and health factors that affect those developments, as well as motor skills, everything from grasping a rattle to driving a car. Cognitive development includes all the mental processes that are used to obtain knowledge or to become aware of the environment.

Psychosocial development includes development of emotions, temperament, and social skills. ${ }^{(2,}$ p. 5).

Gail Sheehy was one of the first to authoritatively document the basic consumption patterns of ageing individuals or cohorts of individuals based on age. Harry Dent ${ }^{3}$, more recently aligned these patterns to actual accumulated date from the U.S. Bureau of Labor Statistics Consumer Expenditure Survey. Dent's findings can be summarized in the below. The consumer life cycle presented below, uses U.S. Census Bureau data to reflect the median age by which most Americans participate in a given event; for example, our first starter homes are purchased generally around the age of 31.

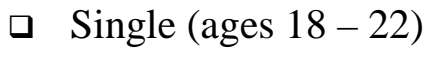

Young Married (ages 22 - 30)

- Average age of first apartment - 26

- Young Family (ages 31 - 42)

- Average age of $1^{\text {st }}$ starter homes - 31

- Average age of trade-up homes - 41 
- Family, College Kids (ages $46-50$ )

- Average age, largest consumption of furniture - 46

口 Empty Nesters (ages 50+)

- Average age for college tuition peak - 51

- Average age for purchases of autos - 53

a Retired (60+)

- Average age for hospital visits - 60

- Average age vacation and retirement homes - 65

- Average age for cruises - 70

- Average age for predominance of prescription drugs - 77

- Average age for nursing homes - 84

As we chronologically age, our life demands for shelter, transportation, food and clothing all are reduced. These many changes are a reflection in large part to our changing family makeup at distinct periods in time. From above, it can be construed our U.S. populace generally get married in their 20's. The 30's are typically a time for the collection of material possessions (cars, homes, furniture, appliances, etc.) Our late 40's reflect an empty nester's phase, where our children become, theoretically, independent and move out onto their own; whether this be college or simply moving away from home to begin working. During our 50's, we begin to notice the changes of primary ageing; that is, those changes related to biological changes in hearing, eye sight, and other physical changes that are frequently the underlying premise for physical ailments and sayings such as “...ageing is not for the faint of heart...”

It becomes considerably more apparent when looking through the above lens to see the overall impact ageing can have on our national economy. Additionally, as documented of recent, millennials skewing purchases to the right places pressure on the entire economic infrastructure designed around historically predictable patterns of purchasing.

In 1950, the median age in the U.S. was 30 years of age. In 200, the median age had increased to 35 years of age. By 2050, the median age in the U.S. will be 40 . As people age, they consume less in terms of material possessions. Those chronologically aged also reduce their earnings and subsequently their taxes, therefore reducing the overall U.S. tax base.

Complimenting this line of thinking, is the required number of working adults 16-64 who pay into Social Security in support of those who draw down from this Government sponsored social support program. The below table reflects the severity of this ratio from 1940 (the first year social security checks were issued) to more recent 2010.

"The Social Security Administration predicts that by 2034, the ratio of workersto-retirees will fall to just 2.1 workers for every retiree as a result of (1) roughly 809 million Baby Boomers retiring and (2) the declining fertility rates having failed to produce a proportionate number of new workers ${ }^{(3, p .108)}$." 


\begin{tabular}{|l|l|l|l|}
\hline \multicolumn{4}{|l|}{ Ration of Workers Paying FICA Taxes to Retirees Collecting Social Security Benefits } \\
\hline Year & Workers (in millions) & $\begin{array}{l}\text { Beneficiaries (in } \\
\text { millions) }\end{array}$ & $\begin{array}{l}\text { Ratio (number of } \\
\text { workers supporting } \\
\text { each retiree) }\end{array}$ \\
\hline 1940 & 35.390 & 0.222 & 159.4 \\
\hline 1950 & 48.2850 & 2.930 & 16.5 \\
\hline 1960 & 72.530 & 14.262 & 5.1 \\
\hline 1970 & 93.090 & 25.186 & 3.7 \\
\hline 1980 & 113.656 & 35.118 & 3.2 \\
\hline 1990 & 133.672 & 39.470 & 3.4 \\
\hline 2000 & 155.295 & 45.166 & 3.4 \\
\hline 2010 & 156.725 & 53.398 & 2.9 \\
\hline Source: Social Security administration (http://www.ssa.gov/history/ratios.html). \\
\hline
\end{tabular}

Figure 2.0 - Number of Workers Supporting Each Retiree

\section{Premised on Age Specific Needs, Motivations Do Change with Age -}

On the whole, the ageing of a populace reduces the need for many of the material purchases frequently associated with chronologically younger cohorts. Typically, younger cohorts have an ever increasing need for financial support. Chronologically aged cohorts, have fewer needs for material possessions, and therefore less of a need for ever increasing financial support. This recognizes the parallelism between increasing needs and increasing financial support.

Looking back then at the above proposed motivational expectancy theory, the equation, effort increases performance, which increase gain, which satisfies personal goals, is modified based on those personal goals being less as, again, chronological ageing occurs. Restated, as personal needs and goals are reduced, financial gains are not as necessary and therefore reduced, which tracks to the original variable, that being less effort is required; and more specifically, our desire to exert higher levels of effort for personal gain is skewed by a weakening of the need for personal gain. 


\section{Career Opportunities and the Short Runway}

Much has been written about the shortfall of skilled workers due to the ageing population. Many have written about the average retirement age for men and women in the United States. More recently, there have been articles on life expectancy of working men and women with college education in non-physical jobs extending past the average life expectancy stated in actuarial tables. A quick Amazon search offers 89,447 books on "careers", 2,333 books on " ${ }^{\text {nd }}$ careers", and 169 books on "ageing careers".

Springer and Schuver ${ }^{4}$ authored a paper documenting the positive benefits of hiring senior retired workers into organizations administering professional fee-based educational programs. Their paper focused on the success and sustainability of their administrative organization. The hiring of senior retired workers provided not only a wealth of knowledge and a different attitude toward work, but different expectations for compensation and reward. They postulated the employment expectations for retired workers are different from chronologically younger employees.

“...senior retired workers want to remain actively involved in, and a part of the greater social construct. They want to continue to contribute in a meaningful way; their motivation is slanted towards self-actualization in the sense they wish to contribute that which they acquired throughout their many life experiences. Senior retired workers are not necessarily motivated by traditional rewards. By this, they are not typically looking to become the next business president, nor are they concerned with receiving the highest pay achievable. They want to be productive members of society and if properly folded into the vision of the organization, bring an unprecedented wealth of knowledge and focus to meeting the organizational challenges.

[Their paper focused] on defining the senior retired worker demographic, looking at the aging of the world's population, examining the proposed shortfall of skilled workers in the United States, examining the science and engineering supply and demand continuum, the international impact, examining the mindset of retired workers, attendant cost implications and applicability to professional development programs and administering organizations...”(p. 1)

Target age populations of this paper, most simplistically, are the current cultural definitions of general cohorts in the workforce based on age demographics and significant defining moments in each age cohort specific lifetime. Although there are documented as many as eight individual cohort groups ${ }^{5}$, in practicality, there are four primary demographic groups in our workforce today ${ }^{6,7}$ :

- Veterans (1922-1946; 52 million population)

- Boomers (1946-1964; 76 million population)

o Began turning 65 in January 1, 2011

口 Gen X (1964-1980; 44 million population) 
a Gen Y (1980-2000; 69.7 million population)

In short, there is significant research and writing on the reality of "having a short runway". In aviation terminology, having a short runway refers to the length of an airport runway for purposes of taking off or landing an aircraft. In Human Resources terminology, having a short runway means something similar, in that an individual may not have enough time to achieve the desired position in a career path; this, given, the additionally required knowledge, skills or experiences required to qualify for said position. Alternatively, it can also mean the years of service remaining is insufficient to achieve, again, the desired career objective position.

To this end, there are significant materials available that discuss a "second career". The above Amazon search reflects some of these 2,333 available books; which does not include the number of research papers delivered at conferences, through journals and made available through centers for ageing or life-long studies.

The recognition of an ageing career, second career and short runway are realities of chronological ageing. Attendant to this recognition is the perceived required education necessary given the seemingly aged life station. As reported in a previous paper ${ }^{4}$, the age of those pursuing Master's degrees through a Center for Professional Studies is 36 years with 15 years of working experience. It is not coincidental, then, given the realities of having a short runway, that educational life-phase pursuits are tied to career opportunities.

\section{Chronological Changes with Age}

Our discussion of like groups within the workforce centers on groups having similar ages, therefore sharing similar experiences and defining moments ${ }^{(8, p .56)}$. Defining moments are those instances where something catches the attention and hearts of hundreds, if not thousands, of individuals at the same basic time in their formative lives.

The list below combines life phases (gerontology) with similar age-related cohort groups in the workforce.

a Late adulthood (60+ years old); Veterans/Baby Boomers

口 Middle adulthood (40-60 years old); Baby Boomers/Generation Xers

口 Early adulthood (20-40 years old); Generation Xers/Generation Y

- Adolescence (10-20 years old); Nexters

글 $\quad$ The school years (7-11 years old)

- Early childhood or preschool (2-6 years old)

Infants or toddlers ( $0-2$ years old) 
This paper focuses on middle through late adulthood; our target age demographics.

When we refer to gerontological life phases, we are referring to the scientific study of human development. The scientific study of human development is the science that seeks to understand how and why people change, and how and why they remain the same, as they grow older ${ }^{(2, \text { p. } 4)}$.

To help individuals to better understand the developmental changes we experience as we grow older, there have been established three domains of human development: biological, cognitive, and psychological.

Biological development includes all of the growth and changes that occur in a person's body, and the genetic, nutritional, and health factors that affect those developments, as well as motor skills, everything from grasping a rattle to driving a car. Social and cultural factors that affect these areas, such as duration of breastfeeding, education of children with special needs, attitudes about ideal body shape, and health habits that extend or shorten human life, are also part of biosocial development.

Cognitive development includes all the mental processes that are used to obtain knowledge or to become aware of the environment. It can include perception, imagination, judgment, memory, and language, the processes people use to think, decide, and learn. Education-including the formal curriculum within schools, informal tutoring by family and friends, and the results of individual curiosity and creativity—is also part of this domain.

Psychological development includes development of emotions, temperament, and social skills. The influences of family, friends, community, culture, and the larger society are particularly central to the psychosocial domain. Thus, cultural differences in the value afforded children, or in ideas about "appropriate" sex roles or what is regarded as the ideal family structure, are primarily explored in this domain ${ }^{(2, \text { p. } 5)}$.

A number of terms are relevant to the senior of these two age cohorts.

- Ageism is a term that refers to prejudice against aged individuals. Its effects are similar to racism and sexism, in that ageism reduces opportunities for elder individuals, which might not normally be withheld had they not been classified as such.

- Gerontology is the study of the aging process. It is one of the fastest-growing fields of study, especially in light of the large number of Baby Boomers quickly moving toward their sunset years. Some gerontologists attempt to draw a distinction between the youngold and the old-old. The young-old are those seniors who make up the large majority of the old. They are generally financially fit, basically healthy, and well integrated into their families and the communities in which they live. The old-old are those who suffer major physical, mental, or social losses and are the most likely to require support in one form or another as they continue to age. 
- Primary aging involves irreversible changes to living organisms as they grow old. Secondary aging, on the other hand, involves physical illnesses or conditions that are more common in aging but are caused by health habits, genes, and other influences that vary from person to person. Recently, however, there has been significant research that indicates that perhaps primary aging can be slowed or, even more interestingly, reversed. This topic is discussed in more detail in later sections.

There are certain biological changes associated with the senior of these two age groups: their hearts begin to beat more slowly, their arteries begin to harden, their digestive organs become less efficient, their lungs lose capacity, sexual responses become slower, sensory organs begin to slow, and the like. These changes and more take place over many decades of this age group. It's not uncommon, for example, for seniors in this age category to have vision problems. Vision diseases in the elderly account for over half the cases of legal blindness in the United States ${ }^{(2, p .}$ ${ }^{611)}$. As this group ages, the pace of these declines increases.

Cognitive discussion begins with an understanding of our sensory system. The sensory register is a part of our memory system that functions for only a fraction of a second during our sensory processing. It retains a fleeting impression of a stimulus that has just been introduced into one of our sense organs. For example, if a person looks at something for a moment and then closes his or her eyes, the image remains briefly for later processing. A significant portion of what gets temporarily stored in the sensory register is transferred to our working memory.

As we age, our sensory registers take longer to store sensed stimulus, and once stored, it fades more quickly. This, coupled with a general overall decline in our sensory systems (eyes, hearing, touch, etc.), leaves some information not only undetected, but that which is may not get registered. Another effect of aging is that we tend to lose our working memory (it's like the Random Access Memory (RAM) in a computers). As well, short-term and long-term memory begin to diminish with age. As individuals pass through the decades that compose this period of life, they also experience difficulty in processing multiple simultaneous inputs, that is, the ability to parallel-process is slowed.

At this phase of life, decision making begins to slow as it takes longer to interpret the data stored in memory. This is caused by the gradual dying off of brain neurons. Brain neurons die at an increasing rate after the age of 60 . During this time, the brain's communication processing slows noticeably, especially after the age of 55 . This causes a general slowing of thought reaction time. Individuals can slow the deterioration of the brain by increasing the blood flow to the brain. This can be done by eating the right foods and exercising.

From a psychological perspective, those in late adulthood who are still working, or even retired, usually remain active. Their activities may include volunteering, pursuing additional education, or being politically involved. 
On the whole, married elders tend to live longer and experience happier and healthier lives than unmarried elders.

\section{Gerontological Phases (Middle Adulthood)}

This group of individuals represent a cohort group called the Baby Boomers. They are far and away the single largest group of people in our workforce today. According to the government's 2001 U.S. Census data, 27.6 percent of our population fall into this age group, compared to 19.6 percent age 60 and over, 26.5 percent from 20 to 40 years of age, and 26.3 percent from 0 to 19 years of age. Collectively, the 35-60 age group may account for as much as 34-35 percent of the U.S. total population.

This can be a trying age group. It's generally around the age of 40 that most people begin to notice that they aren't as young as they once were. Perhaps others have also noticed how Baby Boomers seem to forget things before that they would not have-for example, "What was his name?” This phase of life generally begins to experience the decline of the sensory systems ${ }^{(9, p .}$ 489). Hearing and vision seem to be the first to weaken. Hearing in women begins to show a decline by age 50, while in men it begins much earlier at age 30 . Relative to vision, eyes lose elasticity, therefore impacting depth perception and the ability to adapt to darkness. Both of these changes are

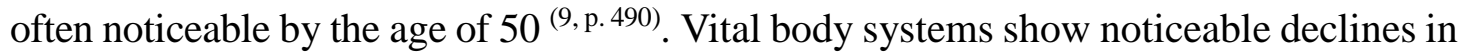
efficiency. Heart, lungs, digestive systems, and immune systems begin to show deterioration. Perhaps most noticeable to women and men alike are changes to the sexual reproduction system. Between the ages of 42 and 58, most women will reach menopause-their menstrual cycle stops, ovulation ceases, and levels of estrogen are reduced. In men, sexual responses continue to slow, sometimes taking longer to respond to a given sexual stimulus ${ }^{\text {(10, p. 397). }}$

Cognitively, overall intelligence improves through early middle adulthood, and intelligence remains stable through middle adulthood. Fluid intelligence, the speed of thinking, experiences small decrements that continue through the early 40s. The speed of decrements increases in speed in later middle adulthood. Crystallized intelligence, which is the practical intelligence, continues to improve with experience, education, and social interaction through the age of 60 .

Relative to midlife psychosocial development:

There is a recognition the number of years remaining are comparable to those already past.

- There is a reexamination of goals, accomplishments, and commitments. This sometimes leads to the well documented midlife crisis.

a Family dynamics are frequently unique, in that those in midlife have growing children and aging adult parents. This has caused those in this cohort to be coined the "sandwich generation.” 
- There tends to be a general shift toward self-improvement, taking on new learning experiences or making lifestyle changes to maintain good health. Those in midlife may enroll in classes at the local universities to take piano lessons or cooking and the like.

- There tends to be a gender crossover within this age group. Women become more assertive, while men are able to express tenderness or sadness more openly.

- Generally, middle adulthood women are less likely to find another spouse than earlier in life, as there are fewer available men.

From the above, chronological aging brings with it many natural changes physically, mentally and psychologically. These many changes, coupled with the recognition of a short runway create an expected change in our perceptions of lifelong learning and the applicability of those educational pursuits to our remaining working adult lives.

\section{Conclusion -}

This paper has reviewed the life-span career educational needs of professional working adult learners. It has reflected on the many aspects forming the underlying premise for changes in those continuing educational needs. At the lowest level are underlying foundational needs of motivation; this given there is an expected and desired outcome from an applied level of effort. The application of this premise was a discussion of the expectancy theory of motivation and its applicability to our target student learner.

In reviewing career progression, an argument was postulated working adult learners are in fact acutely aware of their phase of life and career opportunities attendant to each of those many phases. Aligned to these longitudinal opportunities are recognized educational needs.

This paper also examined the biological, psychological and cognitive changes that have a direct impact on desire and/or willingness to exert energies toward educational pursuits.

This paper framed the learner's perspective and subsequent educational needs, and the value add opportunities of administrative organizations in meeting the needs, of professional working adult learners as they progress through their career life-spans.

In conclusion, from the learner's perspective, there are numerous peripheral, yet directly applicable, factors in why an adult learner would pursue varying types of educational opportunities; motivation, career opportunities, life-phase, human gerontological changes over time all are part of this very complex multi-faceted equation. Recognizing these many variables can provide invaluable information to professional administrative organizations in tailoring their program and course offerings, and, further offers insight into previously documented and discussed age demographics in Master of Science degree offerings. 


\section{References}

1 Robbins, S. (1999). Management (5th ed.). Upper Saddle River, NJ: Prentice Hall.

2 Berger, K. S., and Thompson, R. A. (1998). The developing person through the life span (4 ${ }^{\text {th }}$ ed.). New York: Worth.

3 Dent, H. (2014). The Demographic Cliff. New York, NY.: Penguin Group.

4 Springer, M. L., \& Schuver, M. T. (2012). A force multiplier for professional program growth - synergistic effects of hiring senior retired workers. ASEE 2012 Annual Conference Proceedings. San Antonio, TX.

5 Strauss, W., Howe, N. (1991). Generations. New York, N.Y.: William Morrow and Company.

6 Smith, J.W., Clurman, A. (1997). Rocking the Ages. New York, N.Y.: Harper Business

7 Zemke, R., et al. (2000). Generations At Work. New York, N.Y.: AMACOM.

8 Levinson, D. J. (1978). The seasons of a man’s life. New York: Ballantine.

9 Berk, L. E. (2009). Development through the lifespan (5th ed.). Boston: Pearson Education.

10 Boyd, D., and Bee, H. L. (2011). Lifespan development (6th ed.). New York: Pearson Education.

11 Springer, M. L. (2016). Project and program management: A competency-based approach. $3^{\text {rd }}$ ed. West Lafayette, IN: Purdue University Press. 